\title{
Hydroconversion of Perhydrophenanthrene over Bifunctional Pt/H-USY Zeolite Catalyst
}

\author{
Larissa Brito, ${ }^{[a]}$ Gerhard D. Pirngruber, ${ }^{*[a]}$ Emmanuelle Guillon, ${ }^{[a]}$ Florian Albrieux ${ }^{[a, b]}$ and \\ Johan A. Martens ${ }^{[c]}$
}

\begin{abstract}
In petroleum refining, middle distillates are produced via hydroisomerization/hydrocracking processes using bifunctional catalysts often containing ultrastable Y (USY) zeolite. Petroleum fractions serving as feedstock for hydrocracking processes contain a majority of (poly)cyclic hydrocarbon molecules. Few studies on reaction mechanisms of hydrocracking of such polycyclic compounds are available. In this study the tricyclic phenanthrene molecule was used as model compound. Phenanthrene was hydrogenated on a Pt/alumina pre-catalyst to perhydrophenanthrene, and subsequently hydrocracked over $\mathrm{Pt} / \mathrm{H}$-USY zeolite. The feed consisted of $3 \mathrm{wt} . \%$ phenanthrene
\end{abstract}

\section{Introduction}

Nowadays, the oil industry faces a discrepancy between products supplied by refineries and the worldwide demand of clean hydrocarbon fuels. Refiners are using heavier crude oil fractions which are more difficult to convert, and consequently, it becomes more challenging to provide commodities that are in accordance with the market demands and strict environmental legislation. Vacuum gas oil (VGO) is a typical heavy oil cut $\left(\mathrm{C}_{20}-\mathrm{C}_{60}\right)$ that can be converted in refineries by hydrocracking and fluid catalytic cracking. ${ }^{[1]}$ VGO is composed mainly of polycyclic molecules (aromatics and naphthenes), the rings of which must be cracked to obtain lighter fractions, especially gasoline (less than 10 carbon atoms) and middle distillates $\left(C_{10}-C_{22}\right)$, serving as diesel and kerosene. Market trends suggest that in the period from 2020 to 2040, despite an expected shrinking demand for oil products, middle distillates will remain indispensable for the industry and transportation, especially in

[a] Dr. L. Brito, Dr. G. D. Pirngruber, Dr. E. Guillon, Dr. F. Albrieux

Catalysis, Biocatalysis and Separation Division

IFP Energies Nouvelles

Rond-point de l'échangeur de Solaize

69360 Solaize (France)

E-mail: gerhard.pirngruber@ifpen.fr

[b] Dr. F. Albrieux

Analysis Division

IFP Energies Nouvelles

Rond-point de l'échangeur de Solaize

69360 Solaize (France)

[c] Prof. J. A. Martens

Centre for Surface Chemistry and Catalysis

University of Leuven

Celestijnenlaan 200F, 3001 Leuven dissolved in $\mathrm{n}$-heptane. The reaction was performed at $280^{\circ} \mathrm{C}$ and $60 \mathrm{bar}$, with a molar $\mathrm{H}_{2}$ to total hydrocarbon ratio of $7 \mathrm{~mol} /$ mol. The reaction products were analyzed using GCxGC-FID/MS. This detailed analysis enabled identification of the reaction scheme involving skeletal isomerization, ring opening and fragmentation. New mechanistic insight is gained on relative reactivities of bridged and non-bridged tricyclic naphthenes. Preferential hydrocracking routes were identified. The study provides insight in the products to be expected from polycyclic hydrocarbon isomerization and hydrocracking.

emerging countries and, more specifically, in non OECD Asia. ${ }^{[2]}$ In the future, conversion of VGO by hydrocracking processes will be strongly directed towards the production of high quality diesel and kerosene.

Hydrocracking catalysts are bifunctional catalysts. The reaction mechanism of bifunctional catalysis in general terms is understood as a combination of hydrogenation-dehydrogenation reactions on a metal phase, and acid catalyzed reaction steps on acid sites, typically provided by zeolites. ${ }^{[3]}$ The reaction mechanism of bifunctional conversion of aliphatic molecules and mono- and bicyclic naphthenes is well documented. ${ }^{[4]}$ Long alkanes undergo consecutive branching isomerization reactions to monobranched, dibranched and tribranched skeletal isomers which become more and more reactive towards cracking. ${ }^{[5]}$ Monocyclic naphthenes undergo ring contraction and expansion, and in this way interchange carbon atoms between ring and side chain. Exocyclic cracking predominates over endocyclic cracking. ${ }^{[6]}$ The grouping of short side chains by consecutive ring expansion and contraction reactions leads to isobutyl and longer branched substituents that are cracked from the ring. This reaction is known in literature as "the paring reaction". ${ }^{[-9]}$ Bicyclic molecules like decahydronaphthalene first undergo ring opening and enter the conversion pathways of monocyclic naphthenes.

VGO is composed of hydrocarbons with many cycles. ${ }^{[10]}$ Mechanistic insight in hydrocracking pathways of such molecules is difficult to obtain because of the multitude of reaction products. For mastering the conversion of VGO to middle distillates, there is a need for scientific insight in the mechanisms of hydrocracking of typical VGO molecules because extrapolation of the behaviour of small molecules to larger ones of interest to VGO is not possible. The selectivity of reaction among individual cycles of a polycyclic molecule is just one example. Experimental investigations of the reaction path- 
ways of model VGO molecules with carbon numbers higher than 20 in laboratory reactors are practically very challenging because of the solid nature of the feed at ambient temperature. In view of these challenges and needs, we opted for a stepwise approach and selected a tricyclic molecule to expand the collection of documented molecules in hydrocracking beyond naphthenes containing two rings or less. ${ }^{[8,11]}$

The objective of this study was to explore the mechanism governing hydrocracking of perhydrophenanthrene $\left(\mathrm{C}_{14} \mathrm{H}_{24}\right.$ $\mathrm{PHP})$, the fully hydrogenated product from phenanthrene $\left(\mathrm{C}_{14} \mathrm{H}_{10}\right)$. The catalyst was a conventional platinum loaded USY zeolite extrudate. A similar system has already been studied in the literature. The authors found that the conversion of PHP proceeds via isomerisation, ring opening and cracking to smaller naphthenes. ${ }^{[12]}$ In the present work, the use of twodimensional GC analysis allowed us to describe and explain the reaction details in much greater detail. A particularly interesting feature of our work is the detection of significant amounts of substituted adamantanes. These compounds have high cetane index and superior diesel quality. ${ }^{[13]}$ We could also analyse the ring opening selectivity, i.e. the tendency to open the central vs. a terminal ring of PHP isomers. The detailed knowledge of the structure of ring opening products allowed us in turn to rationalise the distribution of cracked products.

The organisation of the paper is as follows: We first describe the distribution of isomerisation, ring opening and cracking products in great detail in the results section. Based on this analysis, a global reaction scheme is proposed in the discussion section. We then focus on possible reaction pathways leading from the detected ring opening to cracking products. Finally we discuss and explain the observed carbon number distribution in the cracked products.

\section{Results}

\section{Identification and quantification of reaction products with GCxGC-FID/MS}

The 2-dimensional analysis of the hydrogenation products of phenanthrene, obtained on the $\mathrm{Pt} / \mathrm{Al}_{2} \mathrm{O}_{3}$ catalyst is shown in Figure $1 \mathrm{~A}$. Six compounds were present, which are the stereoisomers of perhydrophenanthrene. ${ }^{[14]}$ These six conformational isomers are collectively considered as the feedstock undergoing hydroisomerization and hydrocracking over the bifunctional Pt/ $\mathrm{H}$-USY catalyst loaded downstream of the $\mathrm{Pt} / \mathrm{Al}_{2} \mathrm{O}_{3}$ hydrogenation catalyst. They are collectively referred to as PHP for convenience.

The full GCxGC-FID chromatogram of the reaction products from hydroisomerization/hydrocracking of PHP at $68 \%$ conversion is shown in Figure 2. It illustrates that the reactor effluent is a very complex mixture with over 300 different compounds.

The reaction products were lumped into families, according to their carbon number and structural formula (Figure 3). A first family obtained by skeletal isomerization of PHP is referred to as perhydrophenanthrene isomers, i.e. tricyclic compounds

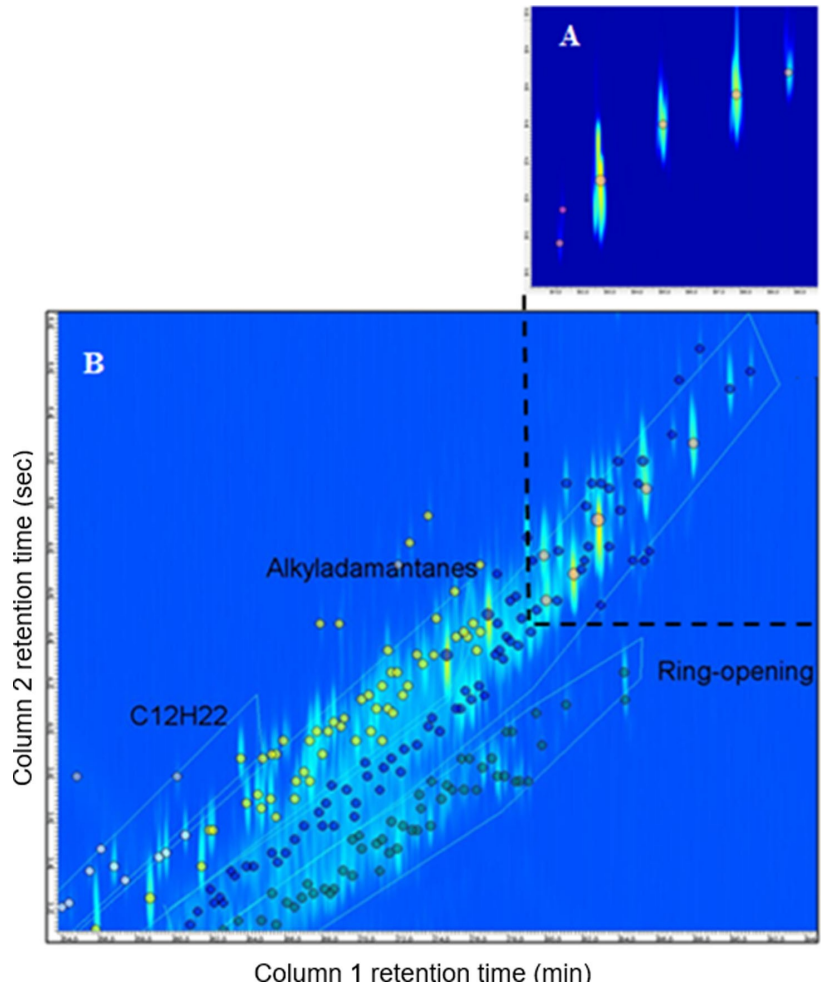

Figure 1. A) GCxGC-FID analysis of perhydrophenanthrene stereoisomers obtained by hydrogenation of phenanthrene over $\mathrm{Pt} / \mathrm{Al}_{2} \mathrm{O}_{3}$ catalyst. B) GCXGC-FID analysis of the heaviest reaction products obtained at $68 \%$ perhydrophenanthrene conversion over Pt/H-USY zeolite catalyst. Integrated signals are noted with blobs. The region where the perhydrophenanthrene stereoisomers appear is indicated with dashed line. Pink blobs are assigned to perhydrophenanthrene stereoisomers, yellow blobs to $C_{14}$ alkyladamantanes, blue to $C_{14}$ skeletal isomers of perhydrophenanthrene, green blobs to $\mathrm{C}_{14}$ ring opening products and white blobs to $\mathrm{C}_{12} \mathrm{H}_{22}$ molecules

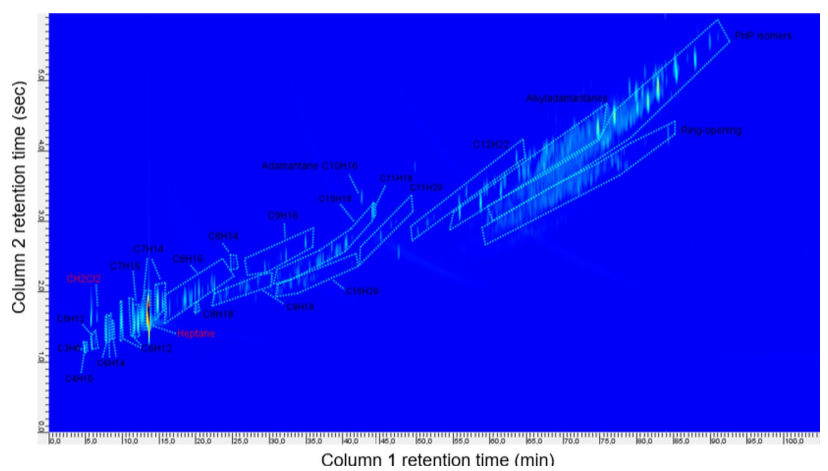

Figure 2. GCXGC-FID analysis of reaction products in the range $C_{3}$ to $C_{14}$ of hydroconversion of perhydrophenanthrene obtained over $\mathrm{Pt} / \mathrm{H}-\mathrm{USY}$ zeolite catalyst at $68 \%$ conversion.

with chemical formula $\mathrm{C}_{14} \mathrm{H}_{24}$. This family is divided into two sub-families: alkyladamantanes and other skeletal isomers of PHP with different arrangements of the rings comprising e.g. perhydroanthracene, methylperhydrophenalenes and ring-contraction products of PHP. Alkyladamantanes are particular in that all of their cycles are 6-rings having armchair conformation. 


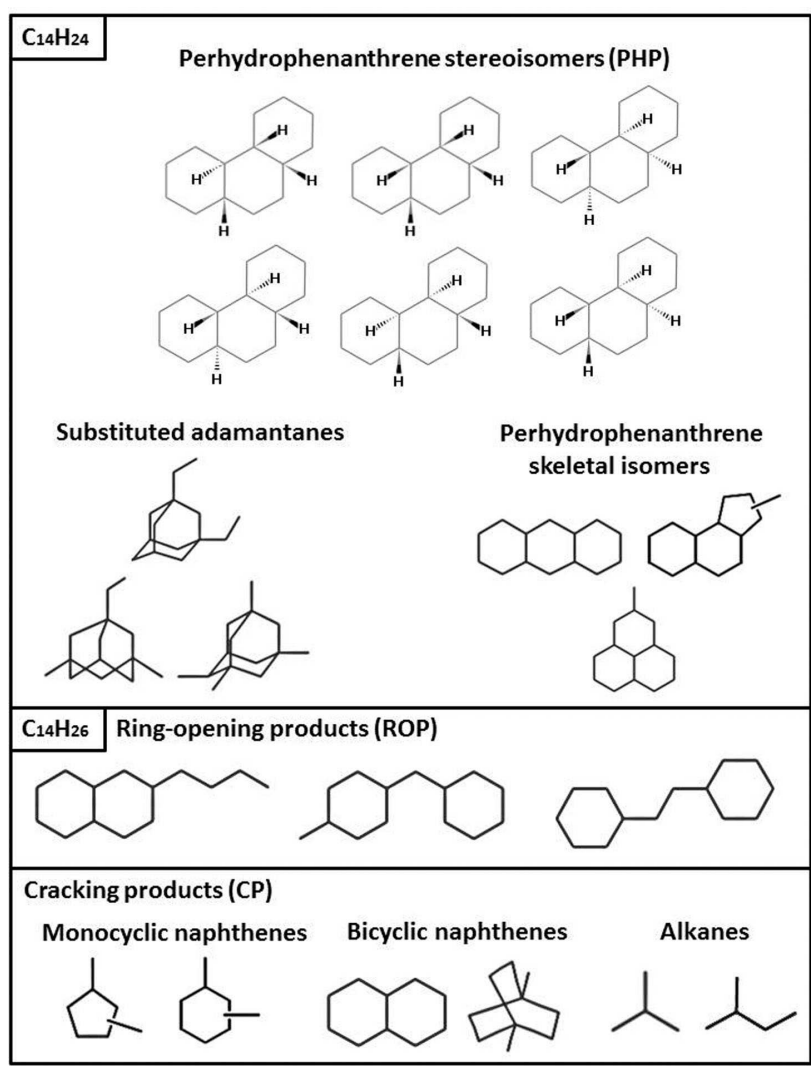

Figure 3. Molecule families and typical examples of reaction products of perhydrophenanthrene stereoisomers hydroisomerization and hydrocracking over Pt/H-USY zeolite catalyst.

Their linking by bridges makes them the thermodynamically the most stable tricyclic structures. ${ }^{[15,16]}$

An additional molecule family with 14 carbon atoms are molecules containing two cycles having chemical formula $\mathrm{C}_{14} \mathrm{H}_{26}$ called ring-opening products (ROP). These are alkylsubstituted decalin isomers obtained by opening of an external ring and alkyl-connected 2-cycle naphthenes obtained by opening of the central ring. Molecules with opening of two out of the three cycles of perhydrophenanthrene were not observed in this study. Figure 1B illustrates the power of twodimensional GC analysis for separating ring-opening products and PHP skeletal isomers from PHP stereoisomers. All molecules with less than $14 \mathrm{C}$-atoms are referred to as cracking products. They essentially comprise mono- or bicyclic structures and, in small amounts, iso- and n-alkanes.

\section{Hydroconversion of perhydrophenanthrene}

The degree of PHP conversion on the Pt/H-USY zeolite catalyst was varied by changing the contact time at a reaction temperature of $280^{\circ} \mathrm{C}$. For the two types of catalyst extrudates with $1 \mathrm{wt} . \%$ and $3 \mathrm{wt} . \%$ USY zeolite, the PHP conversion is plotted against contact time in Figure 4. The catalyst containing $3 \mathrm{wt} . \%$ zeolite was more active than the one containing only $1 \mathrm{wt} . \%$

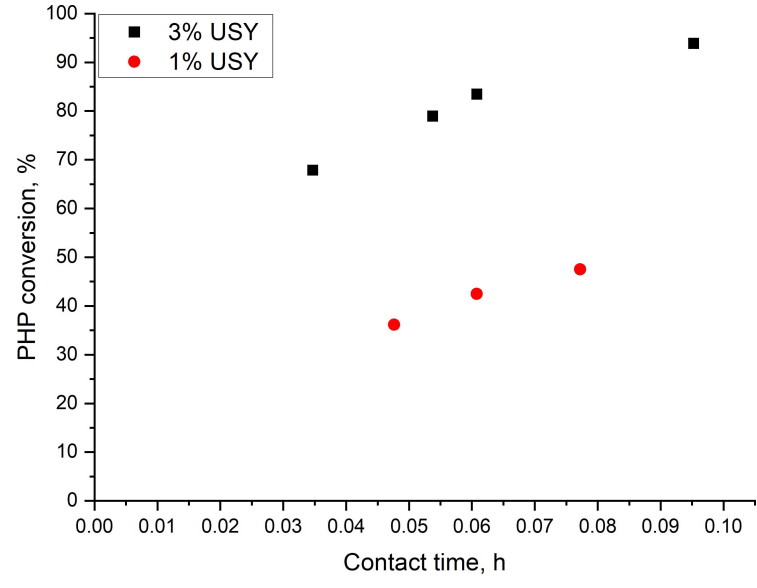

Figure 4. Evolution of PHP conversion with contact time on Pt/H-USY catalyst extrudates with $1 \mathrm{wt} . \%$ and $3 \mathrm{wt} . \%$ zeolite in alumina binder.

zeolite, as expected. The PHP conversion at a given contact time was roughly proportional to the zeolite loading. The data obtained over the two catalysts all together cover the conversion range from $36 \%$ to $94 \%$.

The yield of $\mathrm{C}_{14} \mathrm{H}_{24}$ molecules (skeletal isomers of PHP and alkyladamantanes), $\mathrm{C}_{14} \mathrm{H}_{26}$ molecules with one ring opening and, consequently, having two more $\mathrm{H}$ atoms and cracking products is presented against PHP conversion in Figure 5. PHP isomerization was the predominant reaction at low conversion. The isomerization yield reached a maximum of ca. $43 \%$ at $68 \%$ conversion. $\mathrm{C}_{14} \mathrm{H}_{26}$ ring-opening products are a minority product. Ring opening products reached a maximum yield of about $8 \%$ at $80 \%$ conversion. Cracked products became dominant above $85 \%$ conversion. From the evolution of the yields it is concluded that skeletal isomerization is the primary reaction followed by ring-opening and cracking.

The evolution of the formation of alkyladamantanes and other tricyclic structures within the family of PHP skeletal isomers is presented in Figure 6. The evolution of this

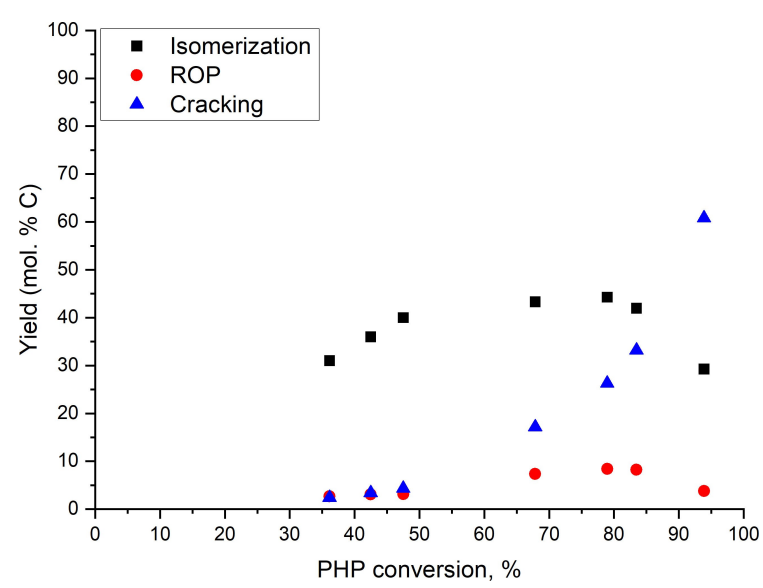

Figure 5. Yield of skeletal isomerization, ring-opening and cracked products against perhydrophenanthrene conversion over $\mathrm{Pt} / \mathrm{H}$-USY zeolite catalyst. 


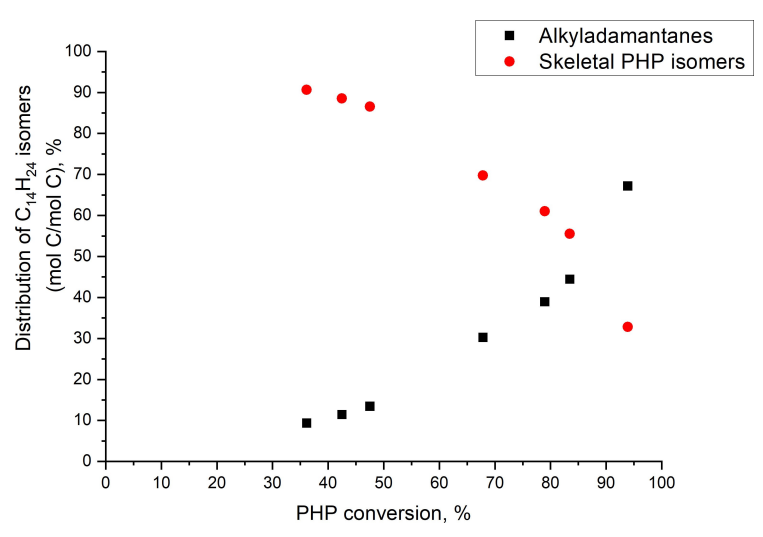

Figure 6. Distribution of $\mathrm{C}_{14} \mathrm{H}_{24}$ reaction products of $\mathrm{PHP}$ conversion over $\mathrm{Pt} /$ $\mathrm{H}$-USY zeolite catalyst against PHP conversion.

distribution with conversion reveals that alkyladamantanes are secondary products obtained from skeletal PHP isomers.

The detailed distribution of PHP skeletal isomers (excluding adamantanes) at different levels of PHP conversion is shown in Figure 7. The most abundant isomers were structures $\mathbf{1 1}$ and 14, i.e. perhydroanthracene stereoisomers denoted PHA, formed by ring-shift of perhydrophenanthrene, ${ }^{[14]}$ and ring-contraction isomers of PHP with one 5-ring and two 6-rings. For the perhydroanthracene stereoisomers there is a discrepancy between their content at low and high PHP conversion. This could be due to an analytical difficulty at low PHP isomerization yield when these molecules are formed in small amounts, which was the case for the data points at 36, 42 and $48 \%$ PHP conversion in the experiment using the catalyst with $1 \mathrm{wt} . \%$ USY zeolite. Ring-contraction isomers (14) formed after isomerization of an external cycle of perhydrophenanthrene were observed at all conversion levels, and their distribution did not change substantially with PHP conversion. Structures resulting from other ring-shift rearrangements of perhydrophenanthrene cycles were also observed, in particular methylperhydrophenalenes (I3). Methylperhydrophenalenes were

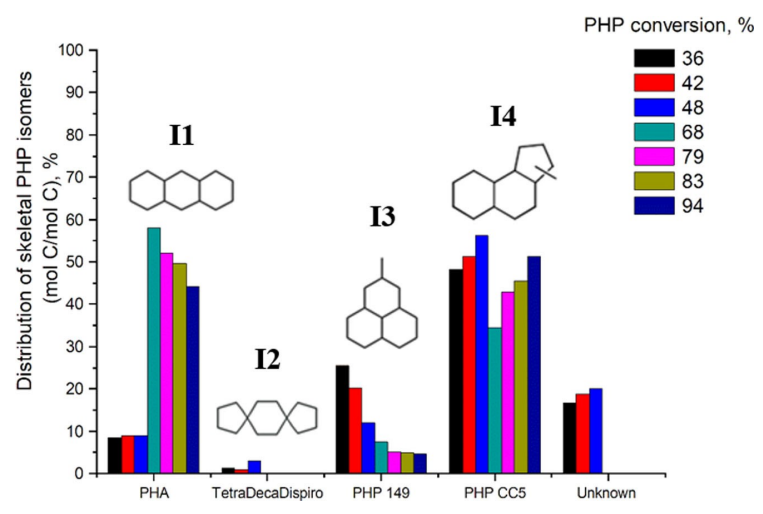

Figure 7. Distribution of skeletal isomers of PHP (excluding substituted adamantanes) at different PHP conversions over Pt/H-USY zeolite catalyst. PHA: perhydroanthracene; PHP 149: methylperhydrophenalenes; PHP CC5: perhydrophenanthrenes that underwent ring contraction. quite abundant at low PHP conversion, but their proportion decreased with conversion. These compounds could be precursors for the formation of alkyladamantanes. ${ }^{[16]}$ Small amounts of more exotic spiro-type compounds (I2), where rings are linked together through a common carbon atom, generating a twisted naphthene, were also formed in low amounts. At low conversion, the unknown fraction accounted for nearly $20 \%$ of the distribution, while at higher conversion almost all compounds could be identified.

The distribution of compounds within the alkyladamantanes subfamily is depicted in Figure 8. This product fraction was rich in structures presenting different types of alkyl substitution. The most abundant isomers were tetramethyladamantanes (A1) and dimethyl-ethyladamantanes (A3). Tetramethyladamantane in comparison to the other substituted adamantanes is the thermodynamically most stable isomer because of its higher number of quaternary carbon atoms. ${ }^{[15]}$ Monoalkylsubstituted structures represented by butyladamantanes (A5) were only present in small amounts, and compounds like methylpropyladamantanes (A4) were observed only at low conversion. The unknown fraction accounted for $10-15 \%$ of the distribution in the investigated PHP conversion range.

The formation of cracked products from PHP implies the breaking of at least two carbon-carbon bonds. Breaking of the first carbon-carbon bond leads to ring opening and formation of alkyl chains on which a second carbon-carbon bond breaking can cause spitting of the $\mathrm{C}_{14}$ molecule into two fragments. PHP stereo and skeletal isomers are more reactive than alkyladamantanes, which accumulate in the $C_{14}$ fraction at increasing PHP conversion (Figure 6). PHP skeletal isomers undergo bridging to form alkyladamantanes and ring-opening followed by cracking (see discussion section).

Ring-opening products comprise a broad spectrum of compounds in terms of substituents and degree of branching (Figure 9). The dominating structures at high PHP conversion were molecules with two cyclohexane rings connected by an alkyl-bridge (R2 and R3). R2, R3 and R5 structures were presumably formed by ring-opening of the central ring of PHP isomers. Products formed by ring opening of an external ring

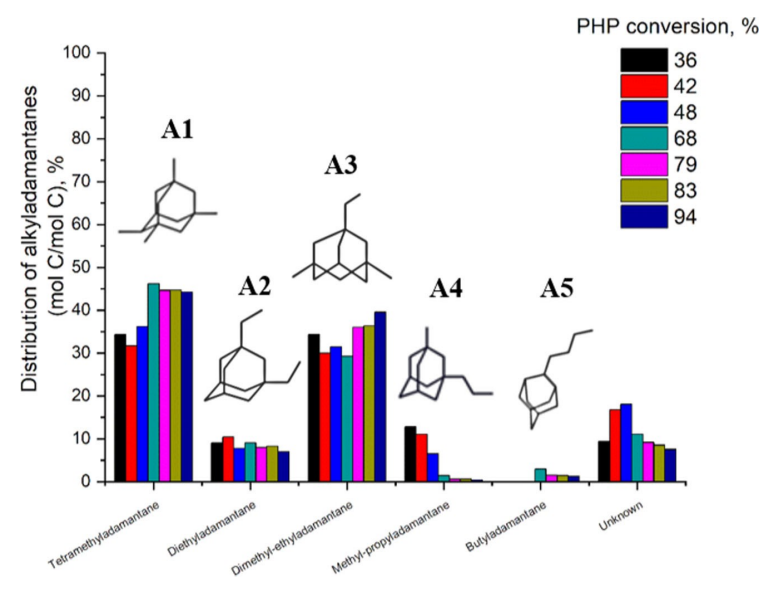

Figure 8. Distribution of alkyl adamantanes at different PHP conversions over Pt/H-USY zeolite catalyst. 


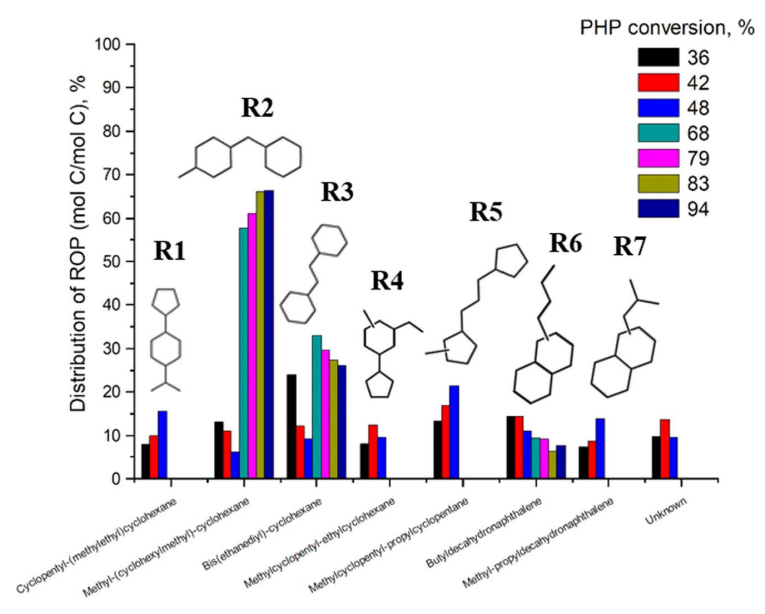

Figure 9. Distribution of ring-opening products (ROP) at different $\mathrm{PHP}$ conversions over Pt/H-USY zeolite catalyst.

were also observed, i.e. structures R6 (butyl-decalins) and R7. Molecules resulting from further rearrangements of PHP cycles resulting in multiple alkyl substituted ROP, such as R1 and R4, were also present. The unknown fraction accounted for $10 \%$ of the distribution at low conversion. Almost all ROP compounds could be identified at high conversion levels.

Around $80 \%$ PHP conversion, cracked products became predominant. The yield of cracked products grouped per carbon number and expressed as the percentage of carbon atoms contained in that fraction is presented in Figure 10. Cracked products had carbon numbers in the range from 3 to 12. Methane and ethane $\left(C_{1}\right.$ and $\left.C_{2}\right)$ and $C_{13}$ products were not formed. Such products are difficult to obtain by bifunctional catalysis and their presence is generally interpreted as being due to hydrogenolysis on metal sites. ${ }^{[17]}$ Significant amounts of $\mathrm{C}_{12}$ were formed especially at low conversion. The formation of $\mathrm{C}_{12}$ products having $2 \mathrm{C}$-atoms less than the feed molecules by cracking of feed isomers would involve elimination of $2 \mathrm{C}_{1}$ groups or a $C_{2}$ group, which is difficult to rationalize with $\beta$ -

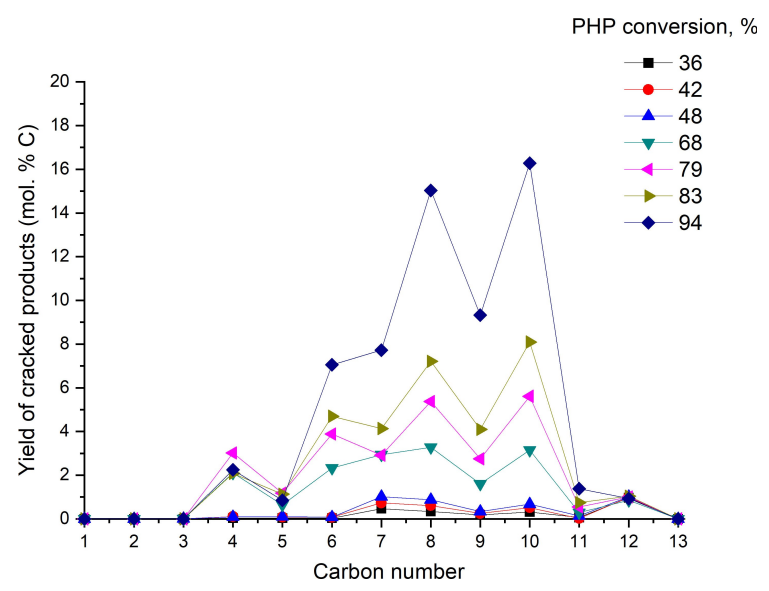

Figure 10. Yield of cracked products according to the number of carbon atoms in the molecules at different levels of PHP conversion over Pt/H-USY zeolite catalyst. scission of alkylcarbenium ions. The yield of $C_{12}$ reaction products did not change with increasing PHP conversion while other fragments in the $C_{4}-C_{10}$ range became more abundant. Propane $\left(C_{3}\right)$ was almost not formed. The cracked product yield distribution according to carbon number showed minima and maxima, i.e. at $\mathrm{C}_{4}, \mathrm{C}_{6}, \mathrm{C}_{8}$ and $\mathrm{C}_{10}$.

The proportion of naphthenes, isoalkanes and $n$-alkanes within the cracked products is revealed in Figure 11. The large majority of the cracked products were naphthenes. Only small amounts of isoalkanes, mainly isobutane, and very little $n$ alkanes were formed. $C_{7}$ isoalkanes were not taken into account, since they were considered as impurities of the solvent ( $n$ heptane).

The yield of cracked naphthenes by carbon number at increasing PHP conversion is available in supporting information (Figure S1). A preferential formation of $C_{10}$ and $C_{8}$ naphthene products was observed, followed by $C_{9}, C_{7}$ and $C_{6}$. $C_{11}$ and $C_{12}$ naphthenes were minority reaction products.

$\mathrm{C}_{6}$ naphthenes were mainly methylcyclopentane (Figure S2 in supporting information). Their distribution did not significantly change with PHP conversion. The distribution of $C_{7}$ naphthenes slightly varied with conversion (Figure 12). Dimethylcyclopentane was formed primarily and isomerized to methylcyclohexane. The content of ethylcyclopentane among the $C_{7}$ naphthenes was almost constant.

The distribution of $C_{8}$ naphthenes did not significantly change with $\mathrm{PHP}$ conversion over $\mathrm{Pt} / \mathrm{H}$-USY zeolite catalyst (Figure S3 in the supporting information). Major products were dimethylcyclohexane positional isomers (C8-1). The content of ethylcyclohexane (C8-2), trimethyl- and methyl-ethylcyclopentane (C8-4 and C8-5, respectively) was about equal. Minor $\mathrm{C}_{8}$ naphthenic products were propylcyclopentane (C8-3) in addition to a small amount of octahydropentalene (C8-6).

The product distribution of $\mathrm{C}_{9}$ naphthenes at different PHP conversions is also provided in the supporting information (Figure S4). On-line analysis of these products at low PHP conversion was somewhat problematic due to the difficulty of

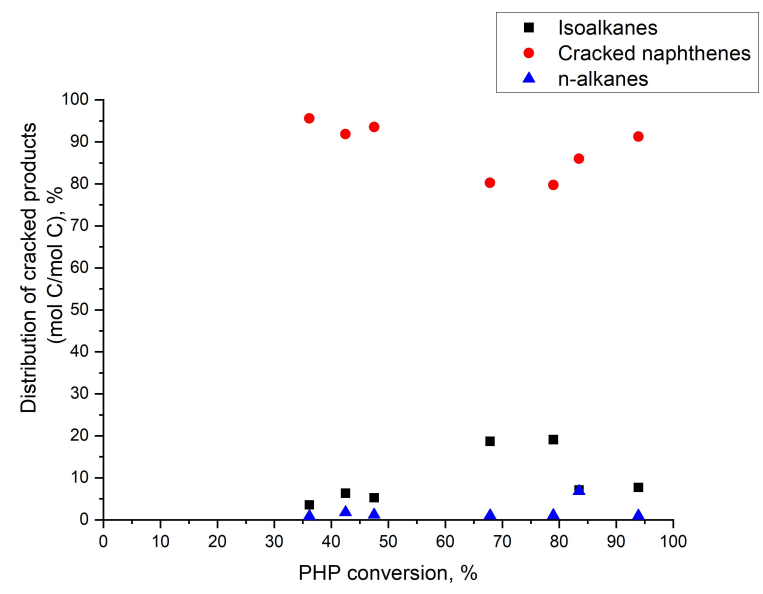

Figure 11. Distribution of naphthenes, isoalkanes and n-alkanes in the cracked products based on C-atom content against PHP conversion over bifunctional Pt/H-USY zeolite catalyst. 


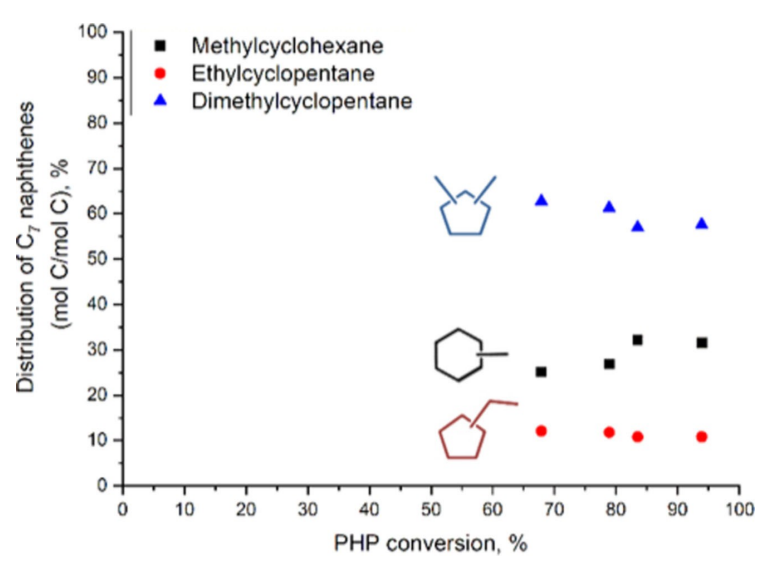

Figure 12. Distribution of $C_{7}$ naphthenes resulting from hydrocracking of PHP over Pt/H-USY zeolite catalyst.

integration of small chromatographic peaks. The distribution at $68 \%$ and higher PHP conversion is reliable. Substituted cyclohexanes, especially di- or tribranched molecules such as C9-4 and C9-5 were dominant at high PHP conversion. Alkyl substituted cyclopentanes were minor products among $\mathrm{C}_{9}$ naphthenes.

The distribution of $\mathrm{C}_{10}$ naphthenes over $\mathrm{Pt} / \mathrm{H}$-USY zeolite catalyst formed preferentially condensed bicyclic naphthenes, as decahydronaphthalene (decalin, C10-7) and its isomers, C103 and C10-4 (Figure 13). Non-substituted adamantane (C10-1), the most stable tricyclic hydrocarbon, was observed at all PHP conversion values, and its distribution remained relatively constant with PHP conversion. Minor products were constituted of substituted cyclohexanes (C10-5 and C10-6, for instance) and twisted naphthenes, as spirodecane (C10-8).

The $C_{11}$ and $C_{12}$ naphthenes were substituted decalin isomers.

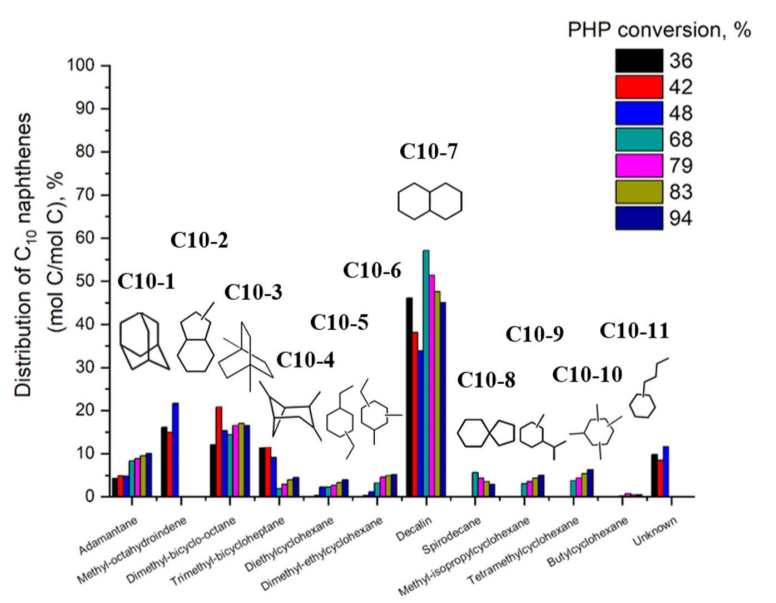

Figure 13. Distribution of $C_{10}$ naphthenes resulting from hydrocracking of PHP over Pt/H-USY zeolite catalyst at different conversions.

\section{Discussion}

\section{Hydroisomerization and hydrocracking reaction pathways}

An analysis of the families of reaction products as a function of PHP conversion (Figure 5 and Figure 6) shows that the primary reaction products were ring-contraction and ring-shift isomers of PHP. Alkyladamantanes with the same number of carbon atoms were formed in a secondary reaction. Ring-opening and cracking were secondary and tertiary reactions, respectively. Alkyladamantanes were final products (Figure 6). A small part of them may have undergone exocyclic cracking explaining the presence of non-substituted adamantane in the $C_{10}$ naphthene fraction (Figure 13), unless the small amount of adamantane is formed via bridging of other $C_{10}$ naphthenes. Based on this analysis a general reaction scheme for hydroconversion of PHP over Pt/H-USY zeolite catalyst is proposed in Figure 14.

The formation of alkyladamantanes from perhydrophenanthrene over acid catalysts $\left(\mathrm{AlBr}_{3}\right.$ sludge) is a well-known phenomenon. ${ }^{[15,16]}$ Substituted adamantanes would be the favored products resulting from isomerization of tricyclic naphthenes, such as perhydrophenanthrene, due to their high thermodynamic stability. Perhydrophenanthrene and alkyladamantanes are almost strain-free molecules, therefore the thermodynamic driving force of the rearrangements is based on the increase in chain branching and the number of quaternary carbon atoms which is enhanced by the bridging in alkyladamantane structures.

The formation mechanism of alkyladamantanes proposed by Schneider et al. (Figure 15) passes by the isomerization to perhydroanthracenes, which undergo ring condensation to methylperhydrophenalenes, and then undergo multiple further rearrangements that ultimately lead to substituted adamantanes with methyl, ethyl, propyl or butyl substituents. In our work, all the intermediates of Schneider's mechanism (Figure 15) were observed among the skeletal PHP isomers (Figure 7, structures $\mathbf{1 1}$ and 13). Notably, the content of methylperhydrophenalene (13) among the PHP skeletal isomers

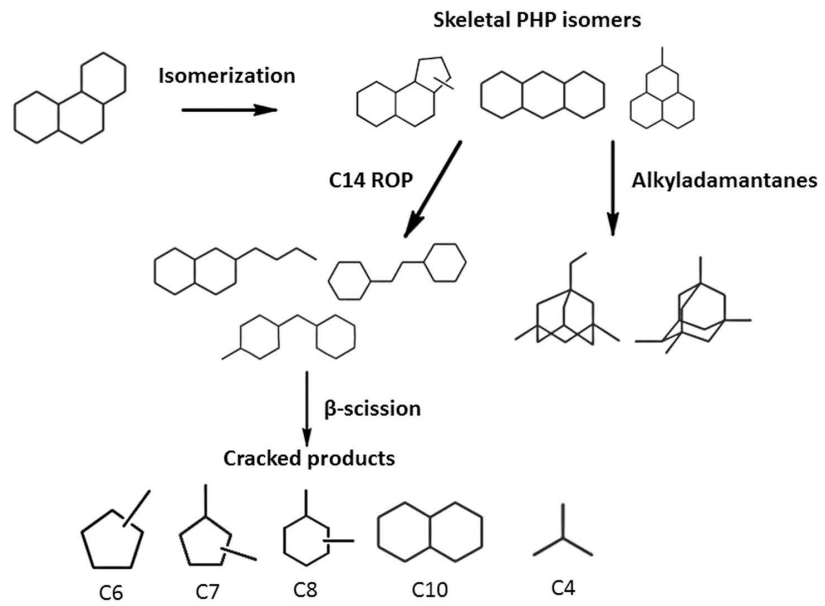

Figure 14. General reaction pathway for hydrocracking of perhydrophenanthrene over bifunctional Pt/H-USY zeolite catalyst. 


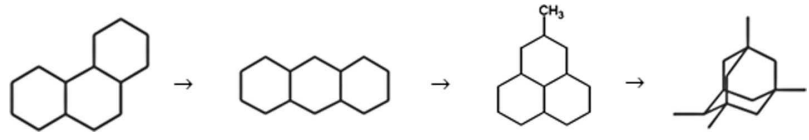

Figure 15. Steps of formation of alkyladamantanes over aluminum bromide sludge catalyst according to Schneider et al.. ${ }^{[16]} \mathrm{A}$ similar reaction pathway is observed in this work in hydrocracking of PHP over Pt/H-USY zeolite catalyst.

decreased with conversion (Figure 7), which could be explained by its conversion to alkyladamantanes (Figure 15). Therefore, the formation mechanism of alkyladamantanes originally proposed for $\mathrm{AlBr}_{3}$ catalysts could also apply to the hydrocracking of perhydrophenanthrene over bifunctional Pt/H-USY zeolite catalysts. Tetramethyl-substituted adamantanes and dimethylethyl-substituted adamantanes having three quaternary carbon atoms are the most stable alkyladamantanes and are most abundant in the reaction products (Figure 8). Few previous studies mentioned the formation of alkyladamantanes among the reaction products. ${ }^{[18,19]}$ These molecules can be overlooked due to a lack of analytical tools which could be used to properly separate and identify them. From a steric point of view, the abundant formation of alkyl-adamantanes in USY zeolite is surprising because the supercage of the faujasite structure probably cannot easily accommodate the bulky structure. ${ }^{[20]}$

Ring-opening and cracking are consecutive reactions to skeletal PHP isomerization (Figure 14). This sequence has also been observed with bicyclic naphthenes. ${ }^{[21]}$ Ring opening does not lead to fragmentation, but is a necessary step to enable splitting of the molecule in two parts in a next step. Opening of an external ring of PHP leads to butyldecalin isomers (Figure 9, structures R6 and R7) whereas the scission of the central ring of PHP results in non-condensed bicyclic naphthenes (Figure 9, structures R2 and R3). The alkyl group linking the two remaining rings is elongated from an initial methyl group (R2) to an ethyl (R3) and propyl (R5). The transformation of R2 to R3 is caused by ring contraction and expansion reaction shifting carbons from alkyl substituents on a ring to the chain linking the rings. The yield of ring-opening products is low (Figure 5) probably because these structures enable fast beta-scission pathways.

The rate of ring-opening depends on the number of tertiary carbon atoms of the molecule in the reactants and products. Figure 8 suggests that the opening of the central ring (to products R2 and R3) is favored over opening of an external ring (products $\mathbf{R} 6$ and $\mathbf{R} 7$ ).

The cracking of ROPs is quite fast, since the ROP concentrations are low (Figure 5). This also explains why mono-cyclic $\mathrm{C}_{14}$ products are not found. As expected from data on substituted mono-cyclic naphthenes, ${ }^{[6-9]}$ cracking to lighter products was faster than a second ring-opening.

\section{Detailed analysis of the hydrocracking reaction pathways}

To shed more light on the hydrocracking reaction pathways and to rationalize the distribution of cracking products, the reaction products theoretically expected by $\beta$-scission of the experimentally observed ROP molecules were compared with the experimental data. We opted to illustrate among the numerous possible reaction pathways only the configurations which lead to fast beta-scission. The reaction rate of $\beta$-scission decreases in the order: tertiary-to-tertiary carbocation $>$ tertiaryto-secondary carbocation and secondary-to-tertiary carbocation $>$ secondary-to-secondary carbocation. Consequently, pathways involving the formation of primary carbocations were not considered. Ring branching is considered to occur, since this step is faster than alkyl-branching. ${ }^{[7]}$

Dehydrogenation and protonation of abundant isomers R2, R3 and R6 (Figure 9) result in several possibilities of carbocations. The cracked products to be expected from these carbocations are discussed here below. Isomers of structure R2 have been evidenced in previous work on hydrocracking of perhydrophenanthrene over bifunctional catalysts. ${ }^{[19,22]}$ Reasonable pathways of hydrocracking of structure $\mathbf{R} \mathbf{2}$, originating from the opening of a central cycle of skeletal perhydrophenanthrene isomers, are exemplified in Figure 16 (A and B). After fast formation of a tertiary carbocation through ring-contraction and hydride shifts, its hydrocracking can lead to the formation of $C_{7}$ naphthenes, i.e. dimethylcyclopentane and methylcyclohexane (Figure 16A). Dimethylcyclopentane may also isomerize into methylcyclohexane (Figure 12). A tertiary carbocation is also obtained after cleavage. The structure $\mathbf{R} 2$ may also provide $C_{6}$ and $C_{8}$ naphthenes as reaction products, undergoing the same type of skeletal rearrangements (Figure 16B). These are tertiary-to-tertiary alkylcarbenium ion types of beta-scission.

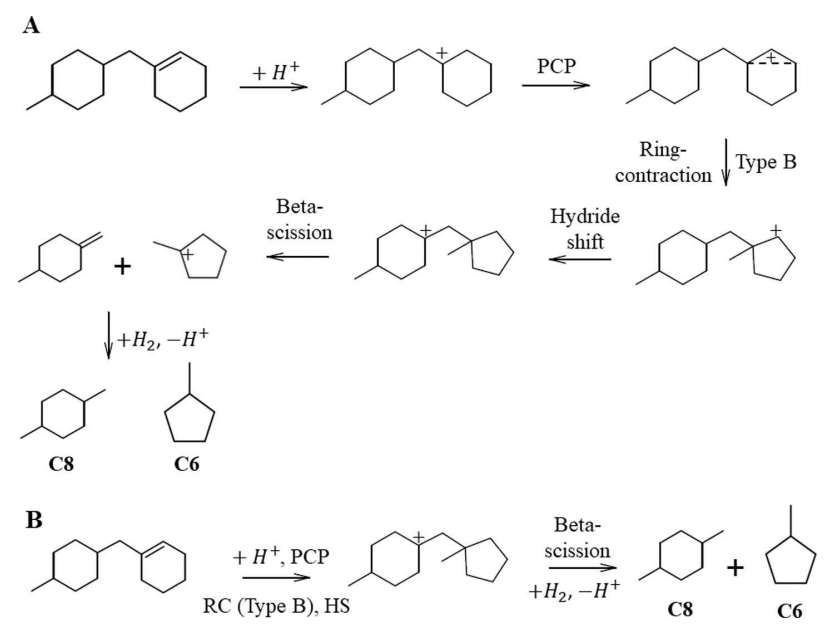

Figure 16. Proposed hydrocracking pathway to $C_{7}$ naphthenes $(A)$ and $C_{6}$ and $C_{8}$ naphthenes $(B)$ of ring-opening products originating from hydroconversion of skeletal perhydrophenanthrene isomers (R2) over $\mathrm{Pt} / \mathrm{H}-\mathrm{USY}$ zeolite catalyst. RC and HS stand for ring-contraction and hydride shift, respectively. 
Hydrocracking pathways of the symmetric isomer R3 (Figure 9) generate $C_{7}$ cyclic structures through scission of tertiary carbocations (Figure 17).

The $\mathbf{R} \mathbf{6}$ isomer is formed through the opening of an external cycle of skeletal perhydrophenanthrene isomers (Figure 9). These intermediates require a branching of the side chain to reach a configuration allowing cracking to decalin and isobutane through a "paring" mechanism (Figure 18). $C_{10}$ naphthenes were indeed mainly represented by decalin (Figure 13). The easiness of R6 (or R7) to crack to $C_{10}$ and $C_{4}$ may explain their low proportion within the family of ring-opening

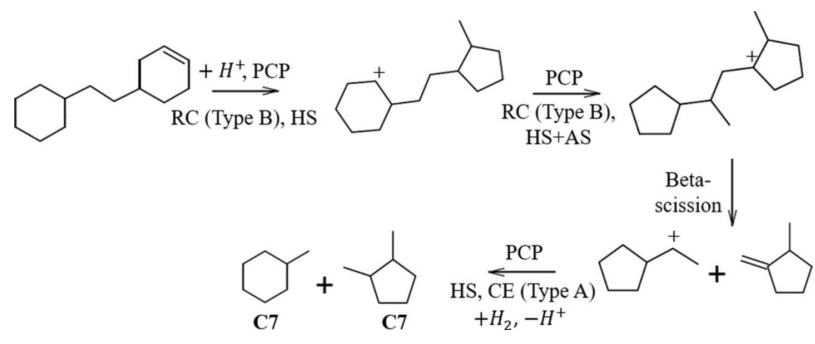

Figure 17. Suggested hydrocracking pathway of ring-opening products originating from hydroconversion of skeletal perhydrophenanthrene isomers (R3) over Pt/H-USY zeolite catalyst, leading to $\mathrm{C}_{7}$ naphthenes. RC: ringcontraction, HS: hydride shift, AS: alkyl-shift, CE: cycle expansion.

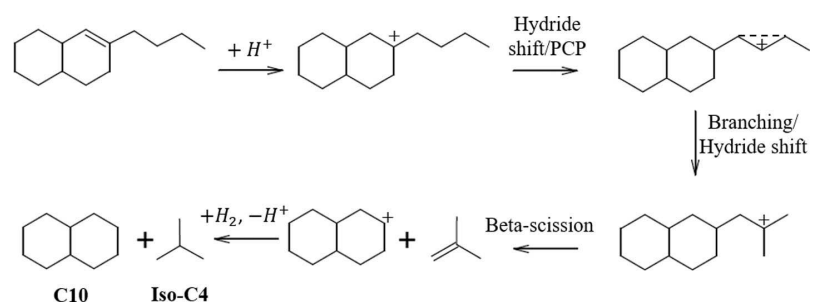

Figure 18. Suggested hydrocracking pathway to $C_{10}$ naphthenes and isobutane of ring-opening product originated from hydroconversion of skeletal perhydrophenanthrene isomers (R6) over Pt/H-USY zeolite catalyst.

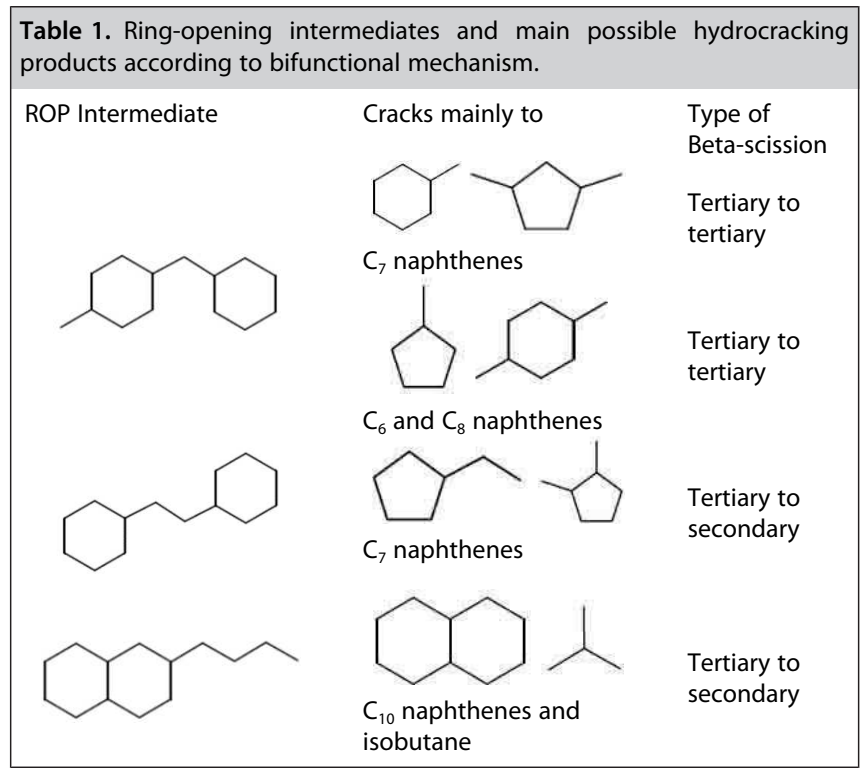

products. Cracking of butyldecalin to $C_{6}, C_{7}$ and $C_{8}$ naphthenes and the corresponding isoalkanes can take place only through opening of an additional cycle. Since the content of isoalkanes other than isobutane within the cracked products was very small, these reactions do not seem to happen.

Ring-opening intermediates and the compounds which they may form via the most favorable cracking routes are summarized in Table 1.

The yield of cracked products (Figure 10) shows maxima at even numbers of carbon atoms. The above analysis of hydrocracking pathways of the main ring-opening products of PHP indeed shows that many favourable cracking pathways lead to $\mathrm{C}_{4}, \mathrm{C}_{6}, \mathrm{C}_{8}$ and $\mathrm{C}_{10}$ products (as well as the symmetric cracking to $C_{7}$ ). In this section we analyze why the formation of cracked products with 5 and 9 carbon atoms is suppressed. Hydrocracking pathways of the ring opening structures R2 and R3 leading to $C_{5}$ and $C_{9}$ naphthenes are presented in Figure 19. Cracking to $C_{9}$ naphthenes and $C_{5}$ isoalkanes proceeds through the opening of a ring, which is a difficult step. ${ }^{[23]}$ In both cases, cracking involves secondary carbocations before and after cleavage, which implies a slow beta-scission. ${ }^{[24]}$

Butyldecalin may be converted into $C_{9}$ naphthenes and $C_{5}$ isoalkanes (Figure 20) through opening of a second ring, similar to the other intermediates. In this case, tertiary and secondary

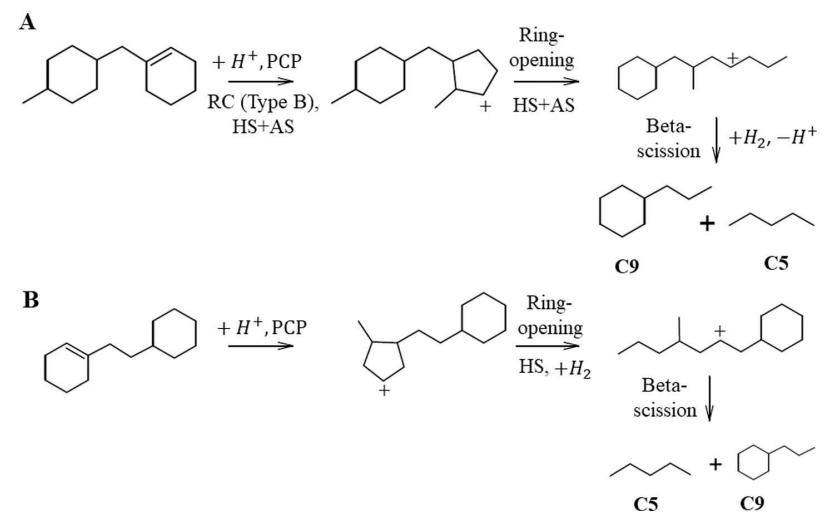

Figure 19. A) Unfavorable hydrocracking pathway to $C_{9}$ naphthenes and $C_{5}$ isoalkanes of ring-opening product originating from hydroconversion of skeletal perhydrophenanthrene isomers (R2) over Pt/H-USY zeolite catalyst. B) Unfavorable hydrocracking pathway to $C_{9}$ naphthenes and $C_{5}$ isoalkanes of ring-opening product originating from hydroconversion of skeletal perhydrophenanthrene isomers (R3) over $\mathrm{Pt} / \mathrm{H}$-USY zeolite catalyst. All pathways show subsequent steps to dehydrogenation over the metal sites. $\mathrm{RC}$ : ring-contraction, HS: hydride shift, AS: alkyl-shift.

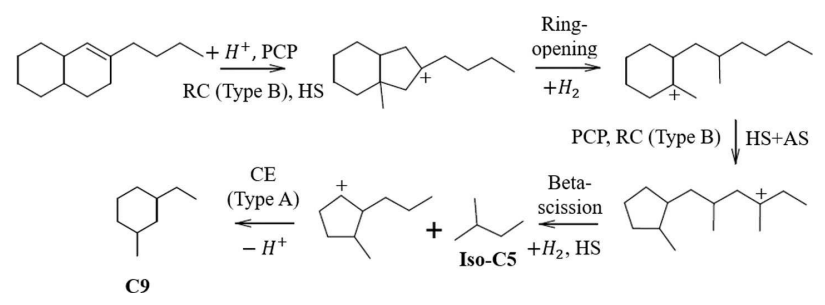

Figure 20. Suggested hydrocracking pathways leading to $C_{9}$ naphthenes and $\mathrm{C}_{5}$ isoalkanes. RC: ring-contraction, HS: hydride shift, AS: alkyl-shift, CE: cycle expansion. 
carbocations were generated before and after cleavage, respectively. The cyclic structure obtained can be isomerized to its 6-membered naphthene through expansion of the $C_{5}$-cyclic structure, producing the $C_{9}$ isomers experimentally observed.

The formation of $C_{6}, C_{8}$ and $C_{10}$ naphthenes does not require opening of the second cycle of the reaction intermediates, which is considered a strained step in a bifunctional mechanism. Therefore, the production of compounds containing an odd number of carbon atoms, such as $C_{9}$ naphthenes and $C_{5}$ isoalkanes, would be less favored over the bifunctional catalyst. The exception is the formation of $C_{7}$ naphthenes, which can be easily generated from intermediates $\mathbf{R} \mathbf{2}$ and $\mathbf{R} 3$, as previously described.

\section{Attempts to rationalize the yield of cracked products}

To enable a discussion of contributions of hydrocracking pathways, it is convenient to express the cracked product yields as mol per $100 \mathrm{~mol}$ of PHP cracked. Primary hydrocracking results in the formation of $200 \mathrm{~mol}$ of cracked products per $100 \mathrm{~mol}$ of feed cracked. Values obtained covered, instead, a range from ca. 154 to $200 \mathrm{~mol} / 100 \mathrm{~mol}$ of cracked PHP. Values below $200 \mathrm{~mol}$ per $100 \mathrm{~mol}$ cracked mean that next to cracking, some oligomerization of feed molecules and/or cracked products takes place.

The yields of cracked product fractions according to carbon number is presented in Figure 21.

This phenomenon has been observed in smaller molecules, as n-heptane. Blomsma et al. studied the hydroconversion of $\mathrm{n}$ heptane over bifunctional Pd/H-Beta zeolite catalyst. ${ }^{[25]}$ Cracking of the $C_{7}$ alkane resulted in non-equimolar amounts of $C_{3}$ and $C_{4}$, in addition to formation of $C_{5}$ and $C_{6}$ alkanes. The yield of these cracked products was explained by a dimerizationcracking mechanism, where two molecules of $C_{7}$ would form a $\mathrm{C}_{14}$ molecule cracking e.g. into $1 \mathrm{C}_{4}$ and $2 \mathrm{C}_{5}$ fragments.

In a similar way, a dimerization mechanism, in addition to classic hydrocracking, could explain the low overall molar yields

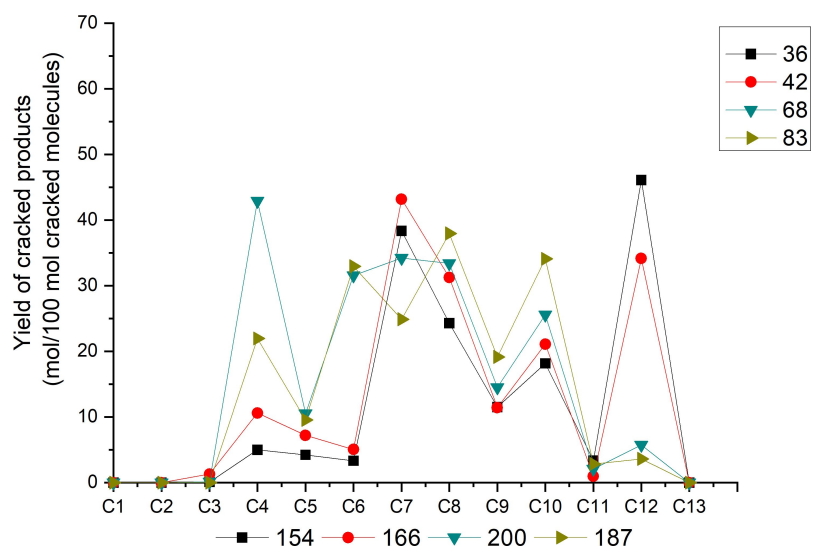

Figure 21. Yield of cracked products from hydrocracking of perhydrophenanthrene over Pt/H-USY zeolite catalyst expressed as mol/100 mol PHP cracked. Total yield of cracked products at the different conversions is indicated at the bottom of the graph. of cracked products per feed molecule cracked. The oligomerization-cracking mechanisms can explain the formation of $\mathrm{C}_{12}$ naphthenes at low PHP conversion. Disproportionation is a reasonable mechanism to explain such a result. In fact, disproportionation has been observed in hydroconversion of naphthenes containing 9 or less carbon atoms over large-pore zeolite-based catalysts, such as $\mathrm{Pt} / \mathrm{CaY}$. Although there are no many evidences on how this reaction works, it is believed that the mechanism goes through the formation of an alkenyl cation, formed after ionic ring-opening, which could alkylate a cyclo-olefin over the acid sites of the zeolite. The resulting structure would then undergo cracking after rearranging favourably to beta-scission. ${ }^{[2]}$ We emphasize, however, that this oligomerization-cracking route is of minor importance at high conversion levels.

\section{Conclusions}

Hydroisomerization and hydrocracking of perhydrophenanthrene $\left(\mathrm{C}_{14} \mathrm{H}_{24}\right)$ were performed over Pt/H-USY zeolite catalyst in order to rationalize bifunctional mechanisms on the conversion of polycyclic naphthenes. Perhydrophenanthrene stereoisomers were formed through in situ hydrogenation of the parent aromatic, phenanthrene, over a $\mathrm{Pt} / \mathrm{Al}_{2} \mathrm{O}_{3}$ pre-catalyst. The conversion of perhydrophenanthrene stereoisomers over the bifunctional extrudate catalyst generated hundreds of reaction products which were exhaustively analyzed with GCxGC-FID/ MS. GCxGC analysis is necessary to be able to distinguish PHP stereoisomers from reaction products and also to identify alkyladamantanes.

The detailed analysis of all reaction intermediates enabled us to propose a reaction pathway for hydroconversion of PHP over the bifunctional catalyst. PHP was first isomerized to ring contraction and ring shift isomers, for example perhydroanthracene. Part of the PHP isomers were converted to stable alkyladamantanes, which resisted hydrocracking. The majority of PHP isomers underwent ring opening. The majority of observed ring opening products resulted from scission of the central ring, but ring opening of the external ring was also observed. The concentration of ring opening products was fairly low because they cracked rapidly to smaller naphthenes. Products of central ring opening preferentially cracked to C6+ C8 or to two C7 naphthenes, while opening of the external ring was followed by a Paring reaction yielding decalin and isobutane. The formation of $\mathrm{C} 5+\mathrm{C} 9$ naphthenes was only possible by unfavorable cracking pathways, hence these products were less abundant. However, the yield of cracked products did not fit with a straightforward cracking of ring opening products to two smaller naphthenes or to a C10 naphthene + isobutane. Probably, other reaction pathways, i.e. dimerization and disproportionation reactions, occur in parallel. 


\section{Experimental Section}

\section{Preparation and characterization of catalysts}

Commercial ultrastable Y zeolite powder (CBV 720 with a Brønsted acid site concentration of $202 \mu \mathrm{mol} / \mathrm{g}$ ) from Zeolyst was shaped in extrudate using Pural SB-3 alumina binder provided by Sasol, according to a procedure described elsewhere. ${ }^{[27]}$ An aqueous solution in a proportion of $62.5 \mathrm{~g}$ water per $100 \mathrm{~g}$ of dry powder, containing $6.50 \mathrm{~g}$ nitric acid per $100 \mathrm{~g}$ dry boehmite, was mixed with USY zeolite and boehmite powder, and stirred with a mixer for 30 minutes, at a frequency of 50 revolutions per minute. A solution composed of $64.5 \mathrm{~g}$ water per $100 \mathrm{~g}$ of dry powder, containing $2.5 \mathrm{~g}$ ammonium per $100 \mathrm{~g}$ of dry boehmite, was then added to the mixture, which was kneaded for 15 minutes, keeping the same frequency of stirring. This paste was then extruded into a trilobe shape extrudate with a diameter of $1.6 \mathrm{~mm}$ and dried overnight at $80^{\circ} \mathrm{C}$. Two supports containing different contents of USY zeolite, 1 and $3 \mathrm{wt} . \%$, respectively, were shaped following this procedure. A trilobe extrudate sample containing only boehmite was also prepared following the same method.

The extrudates were calcined under air flow of $1.5 \mathrm{NL} / \mathrm{h} / \mathrm{g}_{\text {support }}$ at $600^{\circ} \mathrm{C}$ for $2 \mathrm{~h}$. The heating rate was $5^{\circ} \mathrm{C} / \mathrm{min}$. The length of the broken extrudates was selected between 3 and $6 \mathrm{~mm}$.

Selective impregnation of platinum on the alumina binder was performed via ion exchange. In this procedure, the dry support was humidified before the addition of the competitor (chloride ions). The wetted support was mixed with an aqueous solution (4 $\mathrm{g}$ water per $1 \mathrm{~g}$ dry support) containing $1.3 \mathrm{wt} . \%$ of hydrochloric acid. The suspension was stirred for $1 \mathrm{~h}$ and then decanted. After decantation, the extrudates were mixed with another solution $(4 \mathrm{~g}$ water per $1 \mathrm{~g}$ of dry support) containing dissolved chloroplatinic acid hydrate $\left(\mathrm{H}_{2} \mathrm{PtCl}_{6}\right.$, Sigma-Aldrich). The amount of precursor was calculated, assuming quantitative ionic exchange and based on the targeted content of $\mathrm{Pt}$ in the final catalyst. The suspension was then stirred for at least $24 \mathrm{~h}$, decanted and dried overnight at $120^{\circ} \mathrm{C}$.

After drying, calcination was carried out in air flow of $1 \mathrm{NL} / \mathrm{h} / \mathrm{g}_{\text {dry }}$ catalyst, heating rate of $5^{\circ} \mathrm{C} / \mathrm{min}$ and temperature range starting from room temperature up to $520^{\circ} \mathrm{C}$, in steps with $1 \mathrm{~h}$ at $150^{\circ} \mathrm{C}$, $250^{\circ} \mathrm{C}$ and $350^{\circ} \mathrm{C}$, and $2 \mathrm{~h}$ at $520^{\circ} \mathrm{C}$. The calcination in steps minimizes sintering of Pt particles. ${ }^{[28]}$

$\mathrm{Si}$ and $\mathrm{Al}$ contents of the support and Pt content of the final catalyst were determined with X-ray fluorescence (Thermofischer Scientific Advant- $X$ instrument). To this purpose, the samples were crushed and sieved into granulometric particles smaller than $100 \mu \mathrm{m}$.

The dispersion of the $\mathrm{Pt}$ metal on the extrudates was determined via $\mathrm{H}_{2}-\mathrm{O}_{2}$ chemisorption (Gira Xisorb equipment). The samples were calcined following the procedure described above, cooled down to room temperature and purged with helium. Then, a first reduction under hydrogen flow was done at $500^{\circ} \mathrm{C}$ for $2 \mathrm{~h}$. The temperature was decreased to $20^{\circ} \mathrm{C}$ and the samples were purged with Helium flow. Pulses of oxygen gas were used to titrate the platinum hydride contained in the sample. Another purge under Helium flow was applied, and a second reduction with hydrogen at room temperature. After reduction, the catalyst was titrated again with pulses of oxygen gas. The procedure was repeated until the result was stable. The average volume of oxygen corresponding to both titrations is then used for estimating the platinum dispersion based on Equations 1-3. ${ }^{[29]}$

$$
\mathrm{Pt}+\frac{1}{2} \mathrm{H}_{2} \rightarrow \mathrm{Pt}-\mathrm{H}
$$

$\mathrm{Pt}-\mathrm{H}+\frac{3}{4} \mathrm{O}_{2} \rightarrow \mathrm{Pt}-\mathrm{O}+\frac{1}{2} \mathrm{H}_{2} \mathrm{O}$

$$
\mathrm{Pt}-\mathrm{O}+\frac{3}{2} \mathrm{H}_{2} \rightarrow \mathrm{Pt}-\mathrm{H}+\mathrm{H}_{2} \mathrm{O}
$$

Silicon, aluminum and platinum content of the catalysts obtained with X-ray fluorescence, and platinum dispersion values acquired through $\mathrm{H}_{2}-\mathrm{O}_{2}$ titration, are summarized in Table 2. Platinum particle size was estimated from the platinum dispersion by considering a spherical shape of the particles. The concentration of Brønsted acid sites (BAS) was estimated from the content of USY zeolite in the extrudate, by taking into account the concentration of BAS in the parent USY zeolite, derived from the pyridine adsorption capacity and the speciation determined using FTIR as described elsewhere. ${ }^{[30]}$ Textural properties of the commercial USY zeolite are available in literature..$^{[27,31]}$

\section{Catalytic tests}

The reaction was carried out in a fixed-bed downflow reactor tube with an internal diameter of $19 \mathrm{~mm}$. The reactor was loaded with two layers of catalysts of $2 \mathrm{~g}$ each, with Pt/Alumina hydrogenation catalyst mounted upfront of bifunctional Pt/H-USY zeolite catalyst. The hydrogenation pre-catalyst ensured complete hydrogenation of phenanthrene before reaching the hydrocracking catalyst. The catalysts were reduced in situ at $450^{\circ} \mathrm{C}$ for $2 \mathrm{~h}$ under a hydrogen flow of $1 \mathrm{NL} / \mathrm{h} / \mathrm{g}_{\text {catalyst }}$. The heating rate to $450^{\circ} \mathrm{C}$ was $5^{\circ} \mathrm{C} / \mathrm{min}$. The feedstock was composed of $3 \mathrm{wt} . \%$ of phenanthrene (SigmaAldrich) diluted into $97 \mathrm{wt} . \%$ of n-heptane (AnalaR Normapur). With this composition, condensation of feed and reaction products in the reactor unit was avoided. A molar ratio of hydrogen to total hydrocarbons of $7 \mathrm{~mol} / \mathrm{mol}$ was used. The reaction temperature was $280^{\circ} \mathrm{C}$ and total pressure $60 \mathrm{bar}$. In an experiment with $\mathrm{Pt} /$ Alumina catalyst only it was verified that all phenanthrene was hydrogenated before contacting the $\mathrm{Pt} / \mathrm{H}$-USY zeolite catalyst downstream. The weight hourly space velocity was varied from 10 to $30 \mathrm{~g}_{\text {feed }} / \mathrm{g}_{\text {zeolite }} / \mathrm{h}$ by varying the hydrocarbon flow entering the reactor. Catalyst deactivation was not observed over the entire range of operating conditions tested. Carbon balances were between 95 and $97 \%$.

Liquid effluents were condensed and separated from the gas phase reaction products. The latter were analyzed on-line with a GC-FID instrument (Varian) equipped with HP-PONA column provided by Agilent. The liquid products were analyzed off-line by GC-FID and GCxGC-FID/MS. In the GC analysis, the chromatographic peaks were

\begin{tabular}{|c|c|c|c|c|c|}
\hline $\begin{array}{l}\text { USY content in } \\
\text { binder [wt.\%] }\end{array}$ & $\begin{array}{l}\text { Pt load- } \\
\text { ing [wt. } \\
\%]\end{array}$ & $\begin{array}{l}\text { Pt disper- } \\
\text { sion [\%] }\end{array}$ & $\begin{array}{l}\text { Pt particle } \\
\text { size }[\mathrm{nm}]\end{array}$ & $\begin{array}{l}\mathrm{n}_{\mathrm{Pt}} \\
{[\mu \mathrm{mol} /} \\
\mathrm{g}]\end{array}$ & $\begin{array}{l}\text { BAS } \\
{[\mu \mathrm{mol} /} \\
\mathrm{g}]^{[\mathrm{a}]}\end{array}$ \\
\hline 1 & 0.7 & 45 & 2.5 & 9 & 2 \\
\hline 3 & 0.7 & 89 & 1.3 & 18.8 & 6 \\
\hline
\end{tabular}
strongly overlapping in a broad envelope between a retention time

[a] According to BAS concentration of the USY zeolite, viz. $202 \mu \mathrm{mol} / \mathrm{g}$, and the zeolite content of the extrudate assuming that the zeolite it is not affected by the extrusion. 
of 50 to 75 minutes because of the presence of a complex mixture of aliphatic and alicyclic hydrocarbons (cf. Figure S5 in supporting information).

Thus, comprehensive two-dimensional gas chromatography was used for the analysis of the liquid effluent. A gas chromatograph (Agilent 6890) equipped with $50 \mathrm{~m}$ HP-PONA column (Agilent) with internal diameter of $0.2 \mathrm{~mm}$ and film thickness of $0.5 \mu \mathrm{m}$ enabling separation by boiling point was coupled either to a time-of-flight mass spectrometer (LECO) or to a FID. Separation in the second dimension was done with a $3 \mathrm{~m} \mathrm{BPX}-50$ column (SGE), with $0.1 \mathrm{~mm}$ internal diameter, and film thickness of $0.1 \mu \mathrm{m}$, separating the compounds by polarity.

A Zoex thermal modulator was used for controlling the flow of compounds desorbing from the first column and entering the second one. The compounds were thermally desorbed from the first column with hot air, while a nitrogen jet, cooled with a cold unit, trapped the molecules before they could move towards the analysis in the second dimension. The temperature of the hot jet was kept $15^{\circ} \mathrm{C}$ above the temperature of the oven with the chromatographic column. The modulation period was kept constant at $6 \mathrm{~s}$ during the analysis.

Both columns had the same temperature programming, starting from $40^{\circ} \mathrm{C}$ with heating at $2{ }^{\circ} \mathrm{C} / \mathrm{min}$ to $120^{\circ} \mathrm{C}$, then from $120^{\circ} \mathrm{C}$ to $205^{\circ} \mathrm{C}$ at $1{ }^{\circ} \mathrm{C} / \mathrm{min}$ and finally from $205^{\circ} \mathrm{C}$ to $280^{\circ} \mathrm{C}$ at $10^{\circ} \mathrm{C} / \mathrm{min}$. A volume of $1 \mu \mathrm{L}$ of reaction effluent was injected with a split ratio of 100. High-purity helium was used as carrier gas at a constant flow rate of $1 \mathrm{~mL} / \mathrm{min}$. For $\mathrm{MS}$ analysis, the temperature of the ion source and the ionization energy were $200^{\circ} \mathrm{C}$ and $70 \mathrm{eV}$, respectively. Ionization was performed in electron ionization mode. Analysis of reaction products was carried out using GC Image 2.6 software (Zoex), and with NIST MS database (version 08) after converting the data obtained. Mass spectra were compared to those available in the NIST database and in literature. ${ }^{[32]}$

Molar flow of a carbon number fraction (Ni), Conversion $(\mathrm{X})$, yield $(\mathrm{Y})$ and product distributions of specific fractions (D) were derived from the chromatographic analysis of the reaction products using Equations 4-8.

$$
N_{i}=\frac{(\text { wt. } / \text { total } w t .)_{i}{ }^{*} F_{m}{ }^{*} c_{i}}{100^{*} M_{i}}
$$

$F_{m}$ is the mass flow of the feedstock and (wt./total wt.) ${ }_{i}, C_{i}$ and $M_{i}$ the mass fraction, the number of carbons and the molar mass of the component $i$ at the outlet, respectively.

$$
\begin{aligned}
& \mathrm{X}=1-\frac{N_{\text {PHP, out }}}{\sum_{i=1}^{i=14} N_{i, \text { out }}} \\
& Y_{i}=\frac{N_{i}}{\sum_{i=1}^{i=14} N_{i, \text { out }}} \\
& Y_{C_{i}}(\mathrm{~mol} / 100 \mathrm{~mol} \text { cracked })=\frac{1}{i} \sum_{k=1}^{n_{k}} N_{i, k} / \frac{1}{14} \sum_{i=1}^{13} \sum_{k=1}^{n_{k}} N_{i, k}
\end{aligned}
$$

Distribution of component i within the family J:

$$
D_{i, J}=\frac{N_{i \in J}}{\sum N_{i \in J}}
$$

\section{Acknowledgements}

L. Brito would like to thank Pascal Galguen, Charles Leroux and Denis Suida for their technical support on catalyst preparation and catalytic tests; Nadège Cellier, Stéphane Clavel, Yohann Mouillet and Vincent Souchon for their expertise on molecular characterization.

\section{Conflict of Interest}

The authors declare no conflict of interest.

Keywords: phenanthrene • hydroisomerization . hydrocracking - adamantanes - polycyclic naphthenes . bifunctional catalysis - ultrastable $\mathrm{Y}$ zeolite

[1] a) J. Lee, S. Hwang, J. G. Seo, U. G. Hong, J. C. Jung, I. K. Song, J. Ind. Eng. Chem. 2011, 17, 310-315; b) R. Sahu, B. J. Song, J. S. Im, Y.-P. Jeon, C. W. Lee, J. Ind. Eng. Chem. 2015, 27, 12-24.

[2] a) M. Gagnière, A. Pucci, E. Rousseau, "Tackling the gasoline/middle distillate imbalance. An oligomerisation technology can produce a significant increase in middle distillate production", to be found under https://www.axens.net/document/1003/tackling-the-gasoline-middledistillate-imbalance/english.html, 2013; b) Organization of the Petroleum Exporting Countries (OPEC), 2040 World Oil Outlook, 2017.

[3] a) M. Guisnet, Catal. Today 2013, 218-219, 123-134; b) J. Weitkamp, ChemCatChem 2012, 4, 292-306; c) J. W. Thybaut, C. S. Laxmi Narasimhan, J. F. Denayer, G. V. Baron, P. A. Jacobs, J. A. Martens, G. B. Marin, Ind. Eng. Chem. Res. 2005, 44, 5159-5169; d) H. F. Schulz, J. H. Weitkamp, Ind. Eng. Chem. Prod. Res. Dev. 1972, 11, 46-53.

[4] a) D. Kubička, N. Kumar, P. Mäki-Arvela, M. Tiitta, V. Niemi, H. Karhu, T. Salmi, D. Y. Murzin, J. Catal. 2004, 227, 313-327; b) V. Calemma, M. Ferrari, S. Rabl, J. Weitkamp, Fuel 2013, 111, 763-770; c) G. Burnens, C. Bouchy, E. Guillon, J. A. Martens, J. Catal. 2011, 282, 145-154; d) J. A Martens, P. A. Jacobs, J. Catal. 1990, 124, 357-366.

[5] a) F. Alvarez, F. R. Ribeiro, G. Perot, C. Thomazeau, M. Guisnet, J. Catal. 1996, 162, 179-189; b) N. Batalha, A. Astafan, J. C. Dos Reis, Y. Pouilloux C. Bouchy, E. Guillon, L. Pinard, React. Kinet. Mech. Catal. 2015, 114, 661673 ; c) J. A. Martens, P. A. Jacobs, J. Weitkamp, Appl. Catal. 1986, 20, 239-281; d) J. A. Martens, L. Uytterhoeven, P. A. Jacobs, G. F. Froment Stud. Surf. Sci. Catal. 1993, 75, 2829-2832.

[6] G. G. Martens, J. W. Thybaut, G. B. Marin, Ind. Eng. Chem. Res. 2001, 40, 1832-1844.

[7] W. Souverijns, R. Parton, J. A. Martens, G. F. Froment, P. A. Jacobs, Catal. Lett. 1996, 37, 207-212.

[8] C. J. Egan, G. E. Langlois, R. J. White, J. Am. Chem. Soc. 1962, 84, 12041212.

[9] J. Weitkamp, S. Ernst, H. G. Karge, Erdoel Kohle Erdgas Petrochem.. 1984 37.

[10] T. Dutriez, M. Courtiade, D. Thiébaut, H. Dulot, F. Bertoncini, J. Vial, M.-C. Hennion, J. Chromatogr. A 2009, 1216, 2905-2912.

[11] a) S. G. A. Ferraz, B. M. Santos, F. M. Z. Zotin, L. R. R. Araujo, J. L. Zotin, Ind. Eng. Chem. Res. 2015, 54, 2646-2656; b) S. Sayan, B. Demirel, J. Paul, Fuel 2000, 79, 1395-1404; c) K. Sato, Y. Iwata, Y. Miki, H. Shimada, J. Catal. 1999, 186, 45-56.

[12] E. Benazzi, L. Leite, N. Marchal-George, H. Toulhoat, P. Raybaud, J. Catal. 2003, 217, 376-387.

[13] B. G. Harvey, K. W. Harrison, M. C. Davis, A. P. Chafin, J. Baca, W. W. Merriman, Energy Fuels 2016, 30, 10171-10178.

[14] W.-C. Lai, C. Song, A. van Duin, J. W. de Leeuw, Catal. Today 1996, 31, 145-161.

[15] M. A. McKervey, Chem. Soc. Rev. 1974, 3, 479.

[16] A. Schneider, R. W. Warren, E. J. Janoski, J. Org. Chem. 1966, 31, 16171625

[17] A. Haas, PhD thesis, Institut für Technische Chemie, 2012. 
[18] a) L. Wang, Y. Chen, S. Jin, X. Chen, C. Liang, Energy Fuels 2016, 30 3403-3412; b) L. D. Rollmann, L. A. Green, R. A. Bradway, H. K. C. Timken Catal. Today 1996, 31, 163-169.

[19] L. Leite, E. Benazzi, N. Marchal-George, Catal. Today 2001, 65, 241-247.

[20] a) G. C. Lau, W. F. Maier, Langmuir 1987, 3, 164-173; b) J. C. Jansen, E. J. Creyghton, S. L. Njo, H. van Koningsveld, H. van Bekkum, Catal. Today 1997, 38, 205-212.

[21] a) M. Kangas, D. Kubička, T. Salmi, D. Y. Murzin, Top. Catal. 2010, 53 1172-1175; b) C. A. A. Monteiro, D. Costa, J. L. Zotin, D. Cardoso, Fue 2015, 160, 71-79; c) M. A. Arribas, A. Martínez, G. Sastre, Stud. Surf. Sci. Catal. 2002, 142, 1015-1022; d) H. Du, C. Fairbridge, H. Yang, Z. Ring Appl. Catal. A 2005, 294, 1-21.

[22] L. Leite, PhD thesis, Université Paris VI, 2000.

[23] D. M. Brouwer, H. Hogeveen, Recl. Trav. Chim. Pays-Bas 1970, 89, 211 224.

[24] J. Weitkamp, P. A. Jacobs, J. A. Martens, Appl. Catal. 1983, 8, 123-141.

[25] E. Blomsma, J. A. Martens, P. A. Jacobs, J. Catal. 1995, 155, 141-147.

[26] H. Schulz, J. Weitkamp, H. Eberth, (Ed.) 5th Intern. Congr. Catalysis, North-Holland Publishing Co., Amsterdam, 1973, Vol. 2.

[27] P. S. F. Mendes, J. M. Silva, M. F. Ribeiro, A. Daudin, C. Bouchy, J. Ind. Eng. Chem. 2018, 62, 72-83.
[28] P. Gallezot, Catal. Rev. 1979, 20, 121-154.

[29] J. Prasad, K. R. Murthy, P. G. Menon, J. Catal. 1978, 52, 515-520.

[30] P. S. F. Mendes, G. Lapisardi, C. Bouchy, M. Rivallan, J. M. Silva, M. F. Ribeiro, Appl. Catal. A 2015, 504, 17-28.

[31] a) S. C. Larsen, J. Phys. Chem. C 2007, 111, 18464-18474; b) D. Verboekend, N. Nuttens, R. Locus, J. van Aelst, P. Verolme, J. C. Groen, J. Pérez-Ramírez, B. F. Sels, Chem. Soc. Rev. 2016, 45, 3331-3352.

[32] a) A. Polyakova, E. Khramova, Y. Bagrii, N. Tsitsugina, I. Lukashenko, T. Frid, P. Sanin, Petrol Chem U. S. S. R. 1973, 13, 1-10; b) A. V. Kiselev, N. S. Kulikov, G. Curthoys, Chromatographia 1984, 18, 297-304; c) J. W. Greidanus, Can. J. Chem. 1971, 49, 3210-3215; d) R. J. Waltman, A. Campbell Ling, Can. J. Chem. 1980, 58, 2189-2195; e) F. W. McLafferty, F. Turecek, J. Chem. Edu. 1994, 71, 2, A54. 